\title{
Oxygen vacancy-expedited ion diffusivity in transition-metal oxides for high-performance lithium-ion batteries
}

\author{
Xunlu Wang ${ }^{1,2}$, Jie $\mathrm{Liu}^{1}$, Yifan $\mathrm{Hu}^{1,2}$, Ruguang $\mathrm{Ma}^{1,3^{*}}$ and Jiacheng Wang ${ }^{1,2^{*}}$
}

\begin{abstract}
Rapid capacity decay and inferior kinetics are the vital issues of anodes in the conversion reaction for lithium-ion batteries. Vacancy engineering can efficiently modulate the intrinsic properties of transition-metal oxide (TMO)-based electrode materials, but the effect of oxygen vacancies on electrode performance remains unclear. Herein, abundant oxygen vacancies are in situ introduced into the lattice of different TMOs (e.g., $\mathrm{Co}_{3} \mathrm{O}_{4}, \mathrm{Fe}_{2} \mathrm{O}_{3}$, and $\mathrm{NiO}$ ) via a facile hydrothermal treatment combined with calcination. Taking $\mathrm{Co}_{3} \mathrm{O}_{4}$ as a typical example, results prove that the oxygen vacancies in $\mathrm{Co}_{3} \mathrm{O}_{4-x}$ effectively accelerate charge transfer at the interface and significantly increase electrical conductivity and pseudocapacitance contribution. The Li-ion diffusion coefficient of $\mathrm{Co}_{3} \mathrm{O}_{4-x}$ is remarkably improved by two orders of magnitude compared with that of $\mathrm{Co}_{3} \mathrm{O}_{4}$. Theoretical calculations reveal that $\mathrm{Co}_{3} \mathrm{O}_{4-x}$ has a lower $\mathrm{Li}$-insertion energy barrier and more density of states around the Fermi level than $\mathrm{Co}_{3} \mathrm{O}_{4}$, which is favorable for ion and electron transport. Therefore, TMOs with rich vacancies exhibit superior cycling performance and enhanced rate capability over their counterparts. This strategy regulating the reaction kinetics would provide inspiration for designing other TMObased electrodes for energy applications.
\end{abstract}

Keywords: oxygen vacancies, ion diffusion, transition-metal oxide, anode, density functional theory calculation

\section{INTRODUCTION}

With the increasing consumption of traditional fossil fuels, the demand for green and sustainable energy has also increased [1]. Rechargeable lithium-ion batteries (LIBs) are a promising energy storage system in various fields, such as electric vehicles and other energy storage devices [2,3]. However, commercial graphite anodes fail to meet the rapid development of electronic devices because of their low theoretical capacity $\left(372 \mathrm{~mA} \mathrm{~h} \mathrm{~g}^{-1}\right)$, poor rate performance, and unsatisfactory cycling stability [4]. Therefore, anodes with outstanding capacity and fast $\mathrm{Li}^{+}$insertion/desertion should be developed urgently.

Up to now, transition-metal oxides (TMOs) have attracted tremendous attention as potential anodes for LIBs because of their high theoretical specific capacity, low cost, and abundant resources $[5,6]$. However, the practical application of TMOs is limited seriously by two inherent defects. One is the rapid capacity decay caused by huge volume change and particle agglomeration during lithiation/delithiation. The other is the poor rate performance as a result of sluggish ion diffusion kinetics and low electrical conductivity $[7,8] . \mathrm{Co}_{3} \mathrm{O}_{4}$, as a representative TMO, also faces the above-mentioned issues, although it possesses a remarkable theoretical capacity of $890 \mathrm{~mA} \mathrm{~h} \mathrm{~g}^{-1}$ [9-12]. Various approaches have been implemented to mitigate the above drawbacks of $\mathrm{Co}_{3} \mathrm{O}_{4}$ and improve its $\mathrm{Li}$-storage performance. One efficient strategy is to combine $\mathrm{Co}_{3} \mathrm{O}_{4}$ with various carbon materials, such as carbon nanotubes (CNTs) and graphene [13]. Carbon matrix has good electrical conductivity and mechanical strength, which is beneficial to enhancing the electrical conductivity and alleviate volume expansion of anodes simultaneously [14]. However, a large amount of carbon materials in the electrode will reduce the whole capacity, whereas the complex preparation of CNTs and graphene hinders their practical applications [15]. Another effective method is to fabricate various nanostructures, including nanoparticles [16], nanosheets [17], nanorods [18], nanowires [19], and porous hollow spheres $[8,10]$. Nanostructures offer open voids that can effectively facilitate $\mathrm{Li}^{+}$diffusion and alleviate volume expansion and particle agglomeration [20,21]. However, electrodes with a simple nanostructure cannot meet the requirements for high capacity and rate capability of LIBs.

Creating vacancies in crystal lattices could intrinsically change the physicochemical properties of materials. Previous research on oxygen vacancies focused on catalysis [22-26]. Only a few studies analyzed the effect of oxygen vacancies on lithium storage [27]. These limited studies suggest that the introduction of oxygen vacancies can improve electrical conductivity and increase active site, which is beneficial to enhancing lithium storage remarkably [28-31]. For example, Qiu and co-workers [32,33] obtained oxygen-deficient $\mathrm{TiO}_{2}$ with a capacity of $128 \mathrm{~mA} \mathrm{~h} \mathrm{~g}^{-1}$ at $5 \mathrm{C}$ when used as the anode in LIBs. Li et al. [34] synthesized oxygen-vacancy-abundant $\mathrm{ZnCo}_{2} \mathrm{O}_{4}$ for LIBs and found that it exhibited an excellent capacity of $746 \mathrm{~mA} \mathrm{~h} \mathrm{~g}^{-1}$ at $1 \mathrm{C}$. However, the effect of oxygen vacancies in TMOs remains ambiguous. In addition, oxygen vacancies could be successfully introduced into materials by hydrogenation, nonhydrogen reduction, plasma induction, and electrochemical reduction [23,35-37]. However, the practical application of these methods is usually limited by multiple steps, harsh con-

\footnotetext{
${ }^{1}$ State Key Laboratory of High Performance Ceramics and Superfine Microstructure, Shanghai Institute of Ceramics, Chinese Academy of Sciences, Shanghai 201899, China

${ }^{2}$ Center of Materials Science and Optoelectronics Engineering, University of Chinese Academy of Sciences, Beijing 100049, China

${ }^{3}$ School of Materials Science and Engineering, Suzhou University of Science and Technology, Suzhou 215011, China

*Corresponding authors (emails: jiacheng.wang@mail.sic.ac.cn (Wang J); ruguangma@usts.edu.cn (Ma R))
} 
ditions, and high costs.

In the present work, abundant oxygen vacancies are introduced in situ in TMO (e.g., $\mathrm{Co}_{3} \mathrm{O}_{4}, \mathrm{Fe}_{2} \mathrm{O}_{3}$, and $\mathrm{NiO}$ ) nanoparticles through a facile hydrothermal method and a subsequent calcination treatment in air atmosphere. Taking $\mathrm{Co}_{3} \mathrm{O}_{4}$ as a typical example, the as-obtained nanoparticles with abundant vacancies $\left(\mathrm{Co}_{3} \mathrm{O}_{4-x}\right)$ display high electrical conductivity and low impedance owing to the existence of oxygen vacancies. In addition, theoretical calculations prove that the $\mathrm{Li}$ insertion energy barrier of $\mathrm{Co}_{3} \mathrm{O}_{4-x}$ reduces obviously due to the introduction of extra oxygen vacancies. Consequently, the asprepared $\mathrm{Co}_{3} \mathrm{O}_{4-x}$ anode exhibits a high reversible capacity of $1870 \mathrm{~mA} \mathrm{~h} \mathrm{~g}^{-1}$ at a current density of $0.3 \mathrm{~A} \mathrm{~g}^{-1}$ after 200 cycles and an enhanced rate capability of $663 \mathrm{~mA} \mathrm{~h} \mathrm{~g}^{-1}$ even at a current density of $5 \mathrm{~A} \mathrm{~g}^{-1}$. As a general method, the as-synthesized $\mathrm{Fe}_{2} \mathrm{O}_{3-x}$ and $\mathrm{NiO}_{1-x}$ enriched with oxygen vacancies also present much improved electrochemical performance than their counterparts. This vacancy-engineering strategy can inspire the design of advanced electrodes for LIBs based on the inherent properties of materials.

\section{RESULTS AND DISCUSSION}

The synthesis of $\mathrm{Co}_{3} \mathrm{O}_{4-x}$ is schematically presented in Fig. 1a. $\mathrm{Co}_{3} \mathrm{O}_{4-x}$ was fabricated through a facile approach of hydrothermal treatment and subsequent calcination in air. Raw materials including cobalt(II) nitrate hexahydrate, sodium citrate, and sucrose were dissolved in a mixed solvent containing deionized water and absolute ethanol. After the hydrothermal reaction, the as-prepared product was annealed at $400^{\circ} \mathrm{C}$ in air for the in situ introduction of oxygen vacancies into $\mathrm{Co}_{3} \mathrm{O}_{4-x}$ nanoparticles by carbon reduction. The color of the as-prepared product changes from gray to black (Fig. S1), implying that the as-formed oxygen vacancies increase the absorbance of visible light. The control sample $\mathrm{Co}_{3} \mathrm{O}_{4}$ was synthesized using the same method as above, except that sucrose was not added. $\mathrm{Fe}_{2} \mathrm{O}_{3-x}$ and $\mathrm{NiO}_{1-x}$ were also synthesized using the same method, except
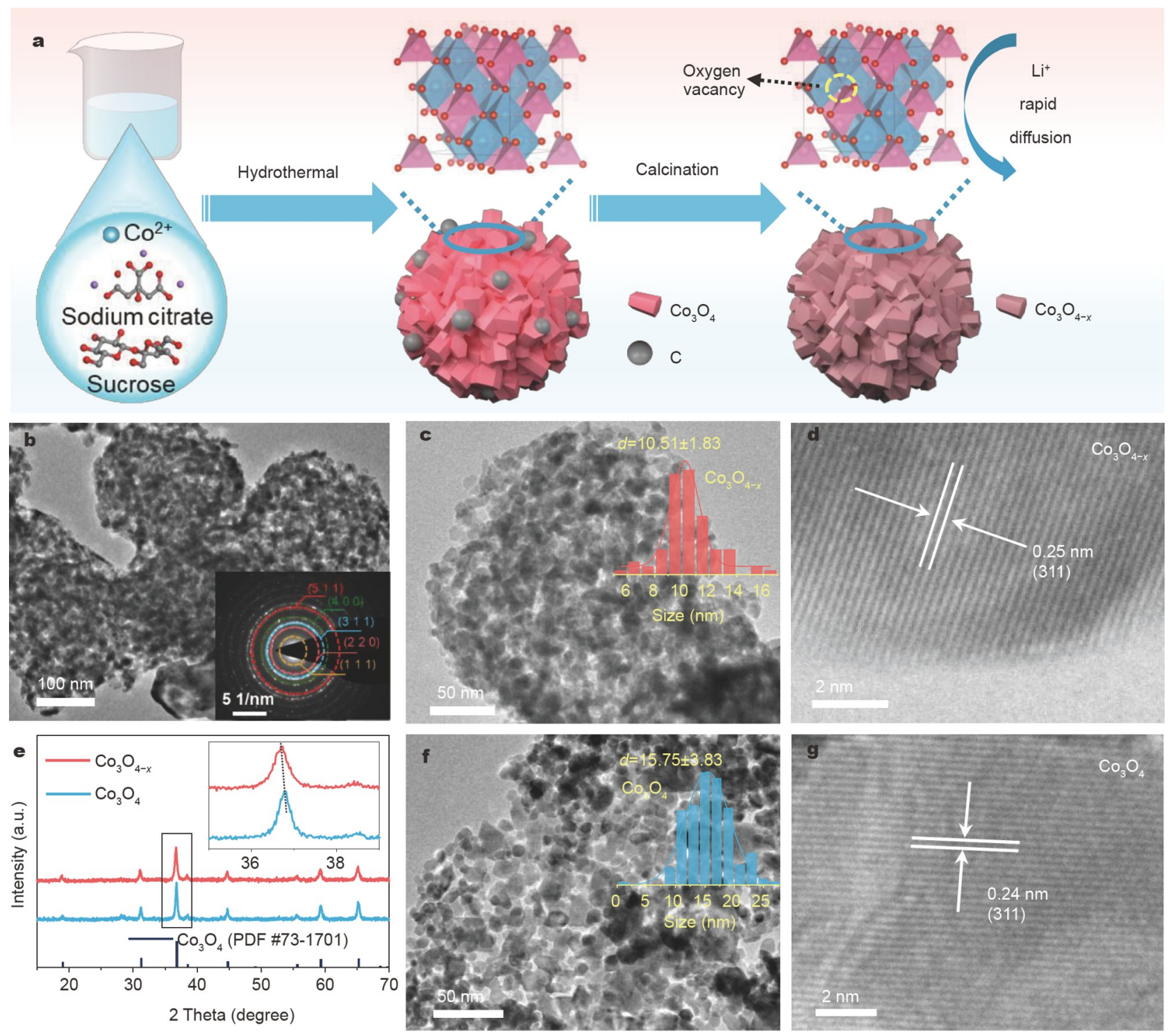

Figure 1 Morphologies and structures of $\mathrm{Co}_{3} \mathrm{O}_{4-x}$ and $\mathrm{Co}_{3} \mathrm{O}_{4}$. (a) Schematic of the synthesis of $\mathrm{Co}_{3} \mathrm{O}_{4-x}$. (b) TEM image (inset of SAED), (c) magnified TEM image (inset of particle size distribution histogram), and (d) HRTEM image of $\mathrm{Co}_{3} \mathrm{O}_{4-x}$. (e) XRD patterns of $\mathrm{Co}_{3} \mathrm{O}_{4-x}$ and $\mathrm{Co}_{3} \mathrm{O}_{4}$. (f) Magnified TEM image (inset of particle size distribution histogram) and (g) HRTEM image of $\mathrm{Co}_{3} \mathrm{O}_{4}$. 
that cobalt nitrate hexahydrate was replaced by the corresponding TM precursors.

The powder X-ray diffraction (XRD) patterns show the crystal structure of all the as-synthesized TMO samples (Fig. 1e and Fig. S2a, b). As shown in Fig. 1e, the diffraction peaks of $\mathrm{Co}_{3} \mathrm{O}_{4-x}$ and $\mathrm{Co}_{3} \mathrm{O}_{4}$ are in accordance with $\mathrm{Co}_{3} \mathrm{O}_{4}$ (JCPDF No. 43-1003), indicating the high purity of the obtained samples. The peak of (311) at approximately $36.8^{\circ}$ shifts to a lower angle, as shown in the inset of Fig. 1e, which can be ascribed to the enlarged interplanar spacing owing to the formation of more oxygen vacancies. No carbon peak can be found in the XRD patterns. In addition, the absence of D-band and G-band peaks in Fig. S3a indicates that the residual carbon content is extremely low. Thermal gravimetric analysis was performed to determine the content of residual carbon in $\mathrm{Co}_{3} \mathrm{O}_{4-x}$. As shown in Fig. S3b, the carbon content in $\mathrm{Co}_{3} \mathrm{O}_{4-x}$ was calculated to be approximately $1.3 \mathrm{wt} \%$. The morphologies and structures of $\mathrm{Co}_{3} \mathrm{O}_{4-x}$ and $\mathrm{Co}_{3} \mathrm{O}_{4}$ were characterized by scanning electron microscopy (SEM) and transmission electron microscopy (TEM). The morphologies of $\mathrm{Co}_{3} \mathrm{O}_{4-x}$ (Fig. 1b, c) and $\mathrm{Co}_{3} \mathrm{O}_{4}$ (Fig. If and Fig. S4) show no obvious difference. The TEM and SEM images (Fig. S5) show that all of them are spherical, uneven nanoparticles with irregular octahedrons. However, the particle size distribution curves (insets in Fig. 1c, f, respectively) show that the particle size of $\mathrm{Co}_{3} \mathrm{O}_{4-x}$ is smaller than that of $\mathrm{Co}_{3} \mathrm{O}_{4}$, which can be ascribed to the fact that the addition of sucrose can prevent the growth of $\mathrm{Co}_{3} \mathrm{O}_{4}$ crystals [38]. The small particle size of $\mathrm{Co}_{3} \mathrm{O}_{4-x}$ can accelerate the ion diffusion and alleviate the huge volume expansion during cycles. Fig. S6 shows the Brunauer-EmmettTeller (BET) surface areas of the two samples. $\mathrm{Co}_{3} \mathrm{O}_{4-x}$ possesses a larger BET surface area of $48.7 \mathrm{~m}^{2} \mathrm{~g}^{-1}$ than $\mathrm{Co}_{3} \mathrm{O}_{4}$ $\left(25.5 \mathrm{~m}^{2} \mathrm{~g}^{-1}\right)$. Larger BET surface areas can enlarge the electrode-electrolyte contact area and provide more available active sites. The inset of Fig. 1b displays the selected area electron diffraction (SAED) patterns of $\mathrm{Co}_{3} \mathrm{O}_{4-x}$, which are in good agreement with the $\mathrm{XRD}$ results, confirming the obtained samples are crystalline $\mathrm{Co}_{3} \mathrm{O}_{4}$. In addition, high-resolution TEM (HRTEM) images provide fine structural information of the samples. As shown in Fig. 1d, the interplanar distance of facet (311) in $\mathrm{Co}_{3} \mathrm{O}_{4-x}$ is enlarged to $0.25 \mathrm{~nm}$ compared with the lattice spacing $(0.24 \mathrm{~nm})$ in $\mathrm{Co}_{3} \mathrm{O}_{4}$, which can be attributed to the expansion of the van der Waals gap caused by the introduction of extra oxygen vacancies. This finding is consistent with the result that the XRD peaks of $\mathrm{Co}_{3} \mathrm{O}_{4-x}$ shift to lower angles (Fig. 1e) [30]. The enlarged interplanar spacing is beneficial to the insertion and extraction of lithium ions in the $\mathrm{Co}_{3} \mathrm{O}_{4-x}$ lattice [39].

The oxygen vacancies can be identified by the electron paramagnetic resonance (EPR) analyses. The EPR signal is attributed to unpaired electrons trapped on surface oxygen vacancies [40,41]. As shown in Fig. $2 \mathrm{a}, \mathrm{Co}_{3} \mathrm{O}_{4-x}$ has a higher EPR intensity value than $\mathrm{Co}_{3} \mathrm{O}_{4}$, suggesting the increasing amounts of oxygen vacancies in $\mathrm{Co}_{3} \mathrm{O}_{4-x}$ [42]. The same phenomenon also occurs in $\mathrm{Fe}_{2} \mathrm{O}_{3-x}$ and $\mathrm{NiO}_{1-x}$. Fig. S2c, d display an obvious signal for $\mathrm{Fe}_{2} \mathrm{O}_{3-x}$ and $\mathrm{NiO}_{1-x}$, which indicates that oxygen vacancies are successfully introduced. Raman spectroscopy was employed to investigate the oxygen vacancies. As shown in Fig. $2 \mathrm{~b}, \mathrm{Co}_{3} \mathrm{O}_{4-x}$ and $\mathrm{Co}_{3} \mathrm{O}_{4}$ exhibit three characteristic peaks that can be ascribed to the spinel $\mathrm{Co}_{3} \mathrm{O}_{4}$ of $\mathrm{E}_{\mathrm{g}}, \mathrm{F}_{2 \mathrm{~g}}$, and $\mathrm{A}_{1 \mathrm{~g}}$ peaks. The peaks for $\mathrm{Co}_{3} \mathrm{O}_{4-x}$ broaden and shift to the left as a result of the increase in
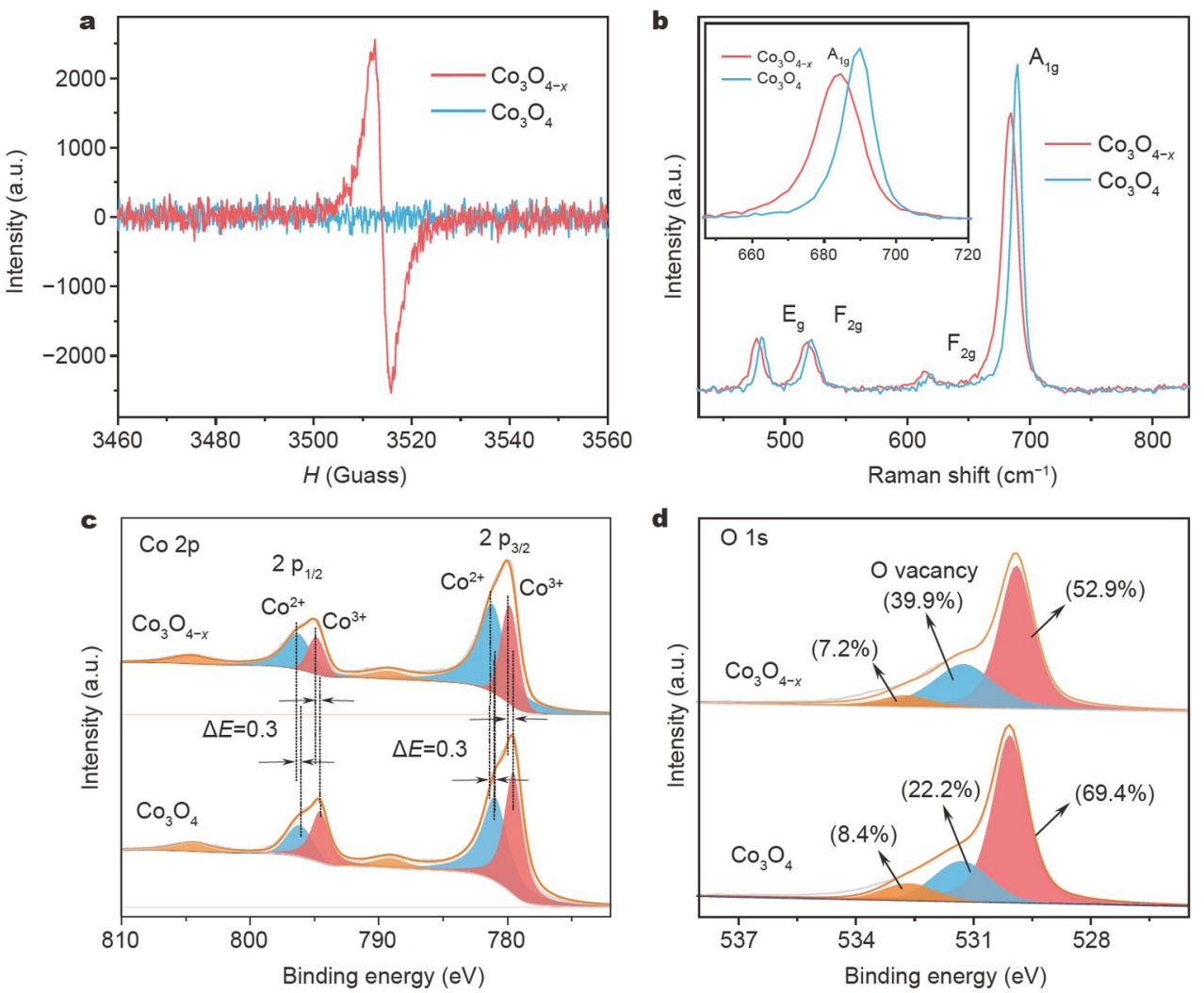

Figure 2 Characterization of oxygen vacancies in $\mathrm{Co}_{3} \mathrm{O}_{4-x}$. (a) EPR spectra, (b) Raman spectra, (c) Co 2p XPS spectra, and (d) O 1 s XS spectra of Co $\mathrm{O}_{4-x}$ and $\mathrm{Co}_{3} \mathrm{O}_{4}$. 
oxygen vacancies (Fig. $2 \mathrm{~b}$ and Table S1, Supplementary information) [43]. X-ray photoelectron spectroscopy (XPS) was conducted to probe the chemical composition and specific chemical states of the as-prepared samples. As shown in Fig. S7a, $\mathrm{b}$, the spectrum of $\mathrm{Co}_{3} \mathrm{O}_{4}$-based samples shows three peaks at approximately 284.6, 529.6, and $795.7 \mathrm{eV}$, which can be attributed to $\mathrm{C} 1 \mathrm{~s}, \mathrm{O} 1 \mathrm{~s}$, and Co $2 \mathrm{p}$, respectively. The $\mathrm{C} 1 \mathrm{~s}$ peak is attributed to carbon dioxide adsorbed on the surface. The atomic contents of $\mathrm{Co}_{3} \mathrm{O}_{4-x}$ and $\mathrm{Co}_{3} \mathrm{O}_{4}$ can be obtained from the spectrum of the samples. As shown in Table $\mathrm{S} 2, \mathrm{Co}_{3} \mathrm{O}_{4-x}$ has a lower ratio of $\mathrm{O} 1 \mathrm{~s} / \mathrm{Co} 2 \mathrm{p}$ than $\mathrm{Co}_{3} \mathrm{O}_{4}$, suggesting the successful introduction of oxygen vacancies.

High-resolution Co $2 \mathrm{p}$ spectra (Fig. 2c) display the characteristic peaks of $\mathrm{Co}^{2+}, \mathrm{Co}^{3+}$, and the satellite (sat.). Two peaks at approximately 779.83 and $794.86 \mathrm{eV}$ correspond to Co $2 \mathrm{p}_{3 / 2}$ and Co $2 \mathrm{p}_{1 / 2}$ of $\mathrm{Co}^{3+}$. Two other peaks at approximately 781.20 and $796.32 \mathrm{eV}$ correspond to the Co $2 \mathrm{p}_{3 / 2}$ and Co $2 \mathrm{p}_{1 / 2}$ of $\mathrm{Co}^{2+}$. The satellite peaks of $\mathrm{Co}^{2+}$ and $\mathrm{Co}^{3+}$ appear at the same binding energy (789.26 and $804.60 \mathrm{eV}$ ) [44]. Importantly, the peaks of $\mathrm{Co}_{3} \mathrm{O}_{4-x}$ positively shift about $0.3 \mathrm{eV}$ when compared with $\mathrm{Co}_{3} \mathrm{O}_{4}$. This result suggests that the $\mathrm{Co}$ element in $\mathrm{Co}_{3} \mathrm{O}_{4-x}$ is more electropositive than that in $\mathrm{Co}_{3} \mathrm{O}_{4}$, which can be attributed to the more abundant oxygen vacancies in the former, accompanied by the redistribution of electron density [45]. On the basis of the integrated area of the peaks, $\mathrm{Co}^{2+}$ accounts for approximately 64.4 at $\%$ of total $\mathrm{Co}$ atoms in $\mathrm{Co}_{3} \mathrm{O}_{4-x}$, which is obviously greater than that in $\mathrm{Co}_{3} \mathrm{O}_{4}(48.5$ at\%). The above results prove that $\mathrm{Co}_{3} \mathrm{O}_{4-x}$ contains more oxygen vacancies than $\mathrm{Co}_{3} \mathrm{O}_{4}$, which can also be supported favorably by the $\mathrm{O} 1 \mathrm{~s}$ spectra of the as-prepared samples. Fig. $2 \mathrm{~d}$ presents three characteristic peaks. The first one at approximately $529.95 \mathrm{eV}$ is attributed to lattice oxygen, the second at approximately $531.23 \mathrm{eV}$ is assigned to the deficiency oxygen, and the last one at approximately $532.50 \mathrm{eV}$ is ascribed to adsorbed hydroxyl species [44]. Obviously, the proportion of deficiency oxygen in $\mathrm{Co}_{3} \mathrm{O}_{4-x}$ is approximately $39.9 \%$, which is higher than that in $\mathrm{Co}_{3} \mathrm{O}_{4}$ (22.2\%) (Fig. S8). These results show that more oxygen vacancies are introduced successfully into $\mathrm{Co}_{3} \mathrm{O}_{4-x}$ than $\mathrm{Co}_{3} \mathrm{O}_{4}$.

Abundant oxygen vacancies can effectively improve the electrical conductivity of $\mathrm{Co}_{3} \mathrm{O}_{4-x}$, as confirmed by the total density of states (DOS) of $\mathrm{Co}_{3} \mathrm{O}_{4-x}$ and $\mathrm{Co}_{3} \mathrm{O}_{4}$. As shown in Fig. 3a, $\mathrm{Co}_{3} \mathrm{O}_{4-x}$ contains more electron DOS than $\mathrm{Co}_{3} \mathrm{O}_{4}$ near the Fermi level, which is desirable for fast electron transport and rapid charge storage [18]. Moreover, the introduction of abundant oxygen vacancies makes a significant contribution to reducing the energy barrier of $\mathrm{Li}$-insertion of $\mathrm{Co}_{3} \mathrm{O}_{4-x}$, which can be proven by density functional theory (DFT) calculations. Fig. $3 \mathrm{~b}$ illustrates the structure models of Li-inserted $\mathrm{Co}_{3} \mathrm{O}_{4-x}$ and $\mathrm{Li}$ inserted $\mathrm{Co}_{3} \mathrm{O}_{4} . \Delta E_{\text {insert }}$ can be obtained using the following equation $[46,47]$ :

$\Delta E_{\text {insert }}=E_{\text {slab-Li }}-E_{\text {slab }}-E_{\mathrm{Li}}$,

where $E_{\text {slab-Li }}, E_{\text {slab }}, E_{\mathrm{Li}}$ correspond to the total energy of $\mathrm{Li}^{-}$ inserted $\mathrm{Co}_{3} \mathrm{O}_{4-x}, \mathrm{Co}_{3} \mathrm{O}_{4-x}$, and $\mathrm{Li}$, respectively. DFT calculations (Table 1) show that $\mathrm{Co}_{3} \mathrm{O}_{4-x}$ contains a lower Li-insertion energy barrier $(-0.406 \mathrm{eV})$ than $\mathrm{Co}_{3} \mathrm{O}_{4}(0.203 \mathrm{eV})$, which implies that the introduction of abundant oxygen vacancies is more beneficial to the intercalation of $\mathrm{Li}$.

The electrochemical properties of $\mathrm{Co}_{3} \mathrm{O}_{4-x}$ and $\mathrm{Co}_{3} \mathrm{O}_{4}$ as the anode of LIBs were evaluated by assembling half-cells with metal lithium. The cyclic voltammetry (CV) curves (Fig. 4a and Fig. S9a) of $\mathrm{Co}_{3} \mathrm{O}_{4-x}$ and $\mathrm{Co}_{3} \mathrm{O}_{4}$ were tested for four cycles at a scan rate of $0.1 \mathrm{mV} \mathrm{s}^{-1}$ to analyze the Li-storage mechanism. As shown in Fig. 4a, an irreversible cathodic peak appears evidently at approximately $0.82 \mathrm{~V}$ in the first discharging curve, which can be ascribed to the irreversible reduction of $\mathrm{Co}_{3} \mathrm{O}_{4-x}$ and the formation of a solid electrolyte interlayer (SEI) [48]. In the subsequent cycles, two cathodic peaks at approximately 1.01 and $1.30 \mathrm{~V}$ are ascribed to the reduction reaction of $\mathrm{Co}_{3} \mathrm{O}_{4} \rightarrow \mathrm{CoO}$ $\rightarrow \mathrm{Co}$, respectively, indicating that the reduction of $\mathrm{Co}_{3} \mathrm{O}_{4}$ involves two processes [15]. During charging, the anodic peak at approximately $2.11 \mathrm{~V}$ corresponds to the oxidation of metal Co and delithiation [49]. The cathodic and anodic peaks overlap in the following repeated scans, which demonstrate the superior
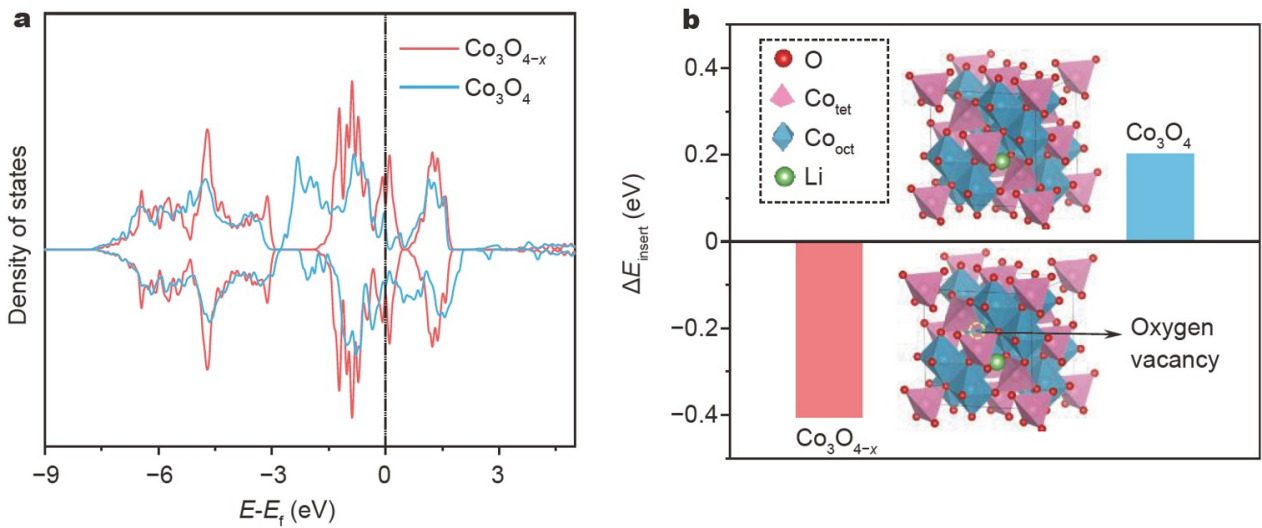

Figure 3 (a) Total DOS plots for $\mathrm{Co}_{3} \mathrm{O}_{4-x}$ and $\mathrm{Co}_{3} \mathrm{O}_{4}$. (b) Calculated $\Delta E_{\text {insert }}\left(\mathrm{eV}\right.$ ) per unit cell for $\mathrm{Co}_{3} \mathrm{O}_{4-x}$ and $\mathrm{Co}_{3} \mathrm{O}_{4}$ (inset of structure models of Li-inserted $\mathrm{Co}_{3} \mathrm{O}_{4-x}$ and Li-inserted $\mathrm{Co}_{3} \mathrm{O}_{4}$ ).

Table 1 Calculated $\Delta E_{\text {insert }}(\mathrm{eV}), E_{\text {slab }}(\mathrm{eV}), E_{\mathrm{Li}}(\mathrm{eV}), E_{\text {slab-Li }}(\mathrm{eV})$ per unit cell for $\mathrm{Co}_{3} \mathrm{O}_{4-x}$ and $\mathrm{Co}_{3} \mathrm{O}_{4}$

\begin{tabular}{ccccc}
\hline Structure & $E_{\text {slab }}(\mathrm{eV})$ & $E_{\mathrm{Li}}(\mathrm{eV})$ & $E_{\text {slab-Li }}(\mathrm{eV})$ & $\Delta E_{\text {insert }}(\mathrm{eV})$ \\
\hline $\mathrm{Co}_{3} \mathrm{O}_{4}$ & -379.636 & -1.995 & -381.428 & 0.203 \\
$\mathrm{Co}_{3} \mathrm{O}_{4-x}$ & -371.374 & -1.995 & -373.775 & -0.406 \\
\hline
\end{tabular}



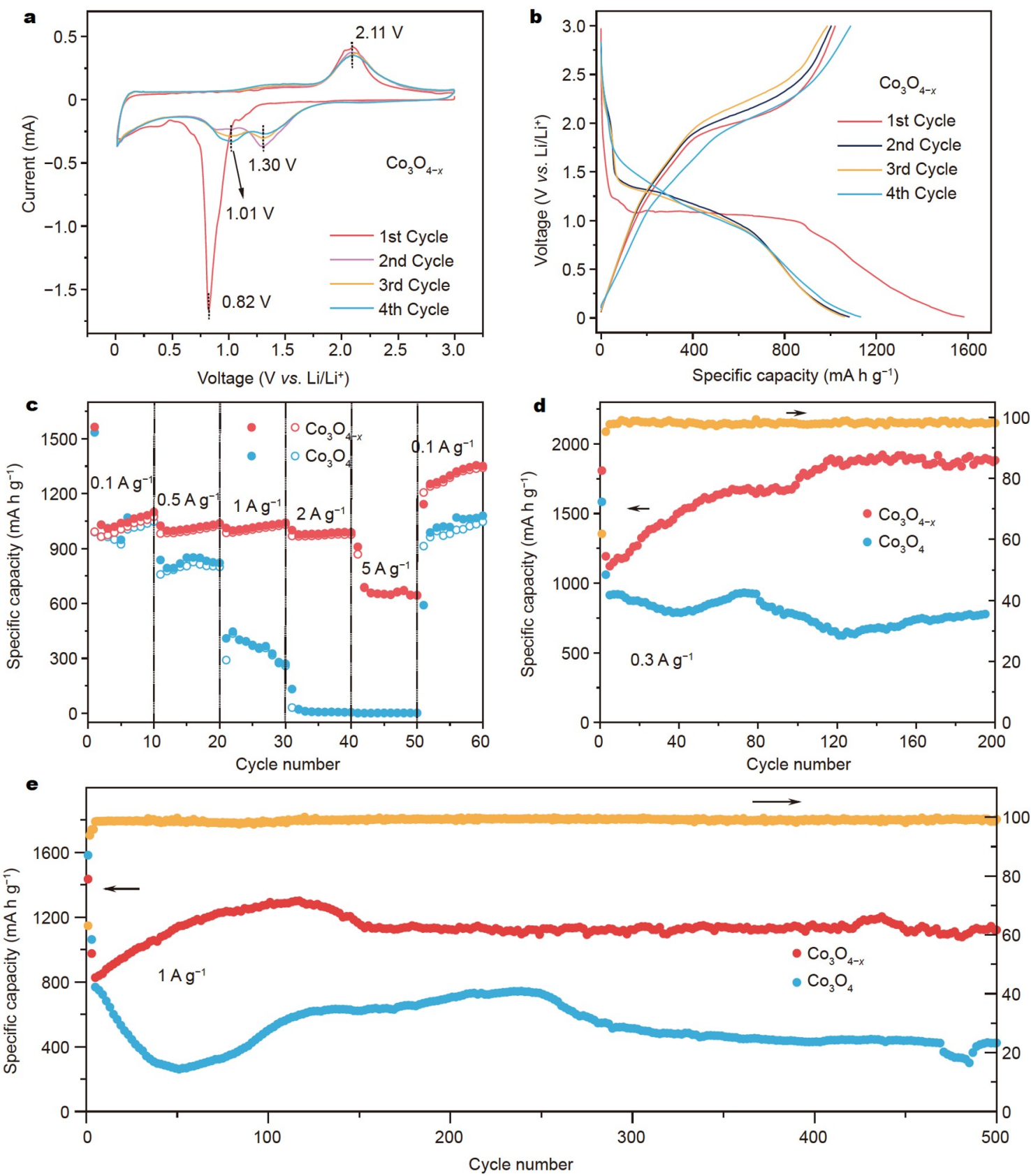

Figure 4 Electrochemical performances of the $\mathrm{Co}_{3} \mathrm{O}_{4-x}$ and $\mathrm{Co}_{3} \mathrm{O}_{4}$ electrodes. (a) CV curves of $\mathrm{Co}_{3} \mathrm{O}_{4-x}$ at a scanning rate of $0.1 \mathrm{mV} \mathrm{s}{ }^{-1}$ and (b) chargedischarge profiles at a current density of $0.1 \mathrm{~A} \mathrm{~g}^{-1}$ for $\mathrm{Co}_{3} \mathrm{O}_{4-x}$. (c) Rate capabilities, (d) cycling performance at a current density of $0.3 \mathrm{~A} \mathrm{~g}^{-1}$, and (e) cycling performance at a current density of $1 \mathrm{~A} \mathrm{~g} \mathrm{~g}^{-1}$ for the $\mathrm{Co}_{3} \mathrm{O}_{4-x}$ and $\mathrm{Co}_{3} \mathrm{O}_{4}$ electrodes.

reversibility of $\mathrm{Li}^{+}$insertion/extraction in the $\mathrm{Co}_{3} \mathrm{O}_{4-x}$ anode. Fig. $4 \mathrm{~b}$ displays the charge-discharge profiles of the $\mathrm{Co}_{3} \mathrm{O}_{4-x}$ electrode at a current density of $0.1 \mathrm{~A} \mathrm{~g}^{-1}$. The voltage plateaus in the profiles are consistent with the $\mathrm{CV}$ peaks. The first discharge and charge specific capacities of the $\mathrm{Co}_{3} \mathrm{O}_{4-x}$ electrode are approximately 1807 and $1116 \mathrm{~mA} \mathrm{~h} \mathrm{~g}^{-1}$ at the current density of $0.1 \mathrm{~A} \mathrm{~g}^{-1}$, corresponding to a coulombic efficiency (CE) of $61.8 \%$. For the $\mathrm{Co}_{3} \mathrm{O}_{4}$ electrode, the first cycle discharge and charge capacities of 1583 and $1020 \mathrm{~mA} \mathrm{~h} \mathrm{~g}^{-1}$ are obtained, respectively. The irreversible capacity loss is attributed to the formation of SEI layer and the electrolyte decomposition [50]. Voltage plateau means the redox reaction of the electrode during the cycle. Therefore, the specific capacity is closely related to the length of voltage plateau [51]. As shown in Fig. $\mathrm{S} 9 \mathrm{~b}, \mathrm{Co}_{3} \mathrm{O}_{4-x}$ has a longer voltage plateau and higher capacities than $\mathrm{Co}_{3} \mathrm{O}_{4}$. The second and third curves show that the $\mathrm{CE}$ of the electrode is significantly improved and the capacity is stabilized, which correspond to the increased reversibility and enhanced cycle stability.

The rate performance of $\mathrm{Co}_{3} \mathrm{O}_{4-x}$ and $\mathrm{Co}_{3} \mathrm{O}_{4}$ at different current densities was measured to investigate the enhanced electrochemical performance of the $\mathrm{Co}_{3} \mathrm{O}_{4-x}$ anode. As shown in Fig. $4 \mathrm{c}, \mathrm{Co}_{3} \mathrm{O}_{4-x}$ exhibits reversible capacities of 1041, 1011, 1020,983 , and $663 \mathrm{~mA} \mathrm{~h} \mathrm{~g}^{-1}$ at current densities of $0.1,0.5,1,2$, and $5 \mathrm{~A} \mathrm{~g}^{-1}$, respectively. Moreover, the reversible capacity of $1350 \mathrm{~mA} \mathrm{~h} \mathrm{~g}^{-1}$ can be achieved when the current density returns 
to $0.1 \mathrm{~A} \mathrm{~g}^{-1}$, which indicates the remarkable stability of the $\mathrm{Co}_{3} \mathrm{O}_{4-x}$ electrode. By contrast, $\mathrm{Co}_{3} \mathrm{O}_{4}$ exhibits inferior rate capacity with reversible capacities of only 1063, 821, 373, 7, and $2 \mathrm{~mA} \mathrm{~h} \mathrm{~g}^{-1}$ at current densities of $0.1,0.5,1,2$, and $5 \mathrm{~A} \mathrm{~g}^{-1}$. Fig. S10 exhibits the charge-discharge profiles of the $\mathrm{Co}_{3} \mathrm{O}_{4-x}$ and $\mathrm{Co}_{3} \mathrm{O}_{4}$ electrodes at current densities of $0.1,0.5,1,2$, and $5 \mathrm{~A} \mathrm{~g}^{-1}$. Obviously, the specific capacity of $\mathrm{Co}_{3} \mathrm{O}_{4}$ decays rapidly with the increase in current density compared with $\mathrm{Co}_{3} \mathrm{O}_{4-x}$. The measurement of rate capacity suggests that $\mathrm{Co}_{3} \mathrm{O}_{4-x}$ can provide faster $\mathrm{Li}^{+}$diffusion, resulting in a superior rate performance than $\mathrm{Co}_{3} \mathrm{O}_{4}$.

Cycling performance is critical to the application of electrodes in LIBs. Fig. $4 \mathrm{~d}$ displays the charge-discharge cycling performance of the $\mathrm{Co}_{3} \mathrm{O}_{4-x}$ and $\mathrm{Co}_{3} \mathrm{O}_{4}$ electrodes at $0.3 \mathrm{~A} \mathrm{~g}^{-1}$. The specific capacity of $\mathrm{Co}_{3} \mathrm{O}_{4-x}$ decreases rapidly in the first few cycles and then gradually increases, which is consistent with other reported TMO anode-based LIBs. As shown in Fig. 4d, $\mathrm{Co}_{3} \mathrm{O}_{4-x}$ retains a specific capacity of $1870 \mathrm{~mA} \mathrm{~h} \mathrm{~g}^{-1}$ approximately after 200 cycles. The inferior specific capacity at the initial cycles can be attributed to the inevitable pulverization of $\mathrm{Co}_{3} \mathrm{O}_{4-x}$ and the repeated formation of an unstable SEI layer. The gradual increase in specific capacity during the repeated charge/discharge processes may be ascribed to the activation and rearrangement in the active material, resulting in more unreacted active sites of the anode exposed to the electrolyte [52]. As shown in Fig. S11, fresh half coin cell possesses the largest charge-transfer resistance, and the charge-transfer resistance gradually decreases as the number of cycles increases. This result is consistent with the increased specific capacity of $\mathrm{Co}_{3} \mathrm{O}_{4-x}$ during the initial cycles. For comparison, $\mathrm{Co}_{3} \mathrm{O}_{4}$ shows a much lower capacity of $777 \mathrm{~mA} \mathrm{~h} \mathrm{~g}^{-1}$ than $\mathrm{Co}_{3} \mathrm{O}_{4-x}$ after 200 cycles at $0.3 \mathrm{~A} \mathrm{~g}^{-1}$ (Fig. $4 \mathrm{~d}$ ). The prolonged cycling performance and $\mathrm{CE}$ of the electrodes were further investigated at a large current density of $1.0 \mathrm{~A} \mathrm{~g}^{-1}$ (Fig. 4e). The specific capacity of $\mathrm{Co}_{3} \mathrm{O}_{4-x}$ also suffers significant fluctuation during cycling, which is common in TMOs in LIBs [53]. In specific, the specific capacity of $\mathrm{Co}_{3} \mathrm{O}_{4-x}$ increases rapidly during the initial 117 cycles, resulting in the activation of the electrode and the formation of SEI film. In addition, the specific capacity $\mathrm{Co}_{3} \mathrm{O}_{4-x}$ can reach approximately $1300 \mathrm{~mA} \mathrm{~h} \mathrm{~g}^{-1}$ after 117 cycles. Then, the specific capacity decay can be reasonably attributed to the unstable SEI film, inevitable pulverization of electrodes, and electrolyte degradation [54]. The electrode particles become smaller; thus, more active sites are exposed to the electrolyte and a stable SEI layer is reformed on the surface. The structural changes of the $\mathrm{Co}_{3} \mathrm{O}_{4}$ and $\mathrm{Co}_{3} \mathrm{O}_{4-x}$ electrodes after 117 cycles at the current density of $1 \mathrm{~A} \mathrm{~g}^{-1}$ were also monitored to prove the importance of oxygen vacancies in maintaining the stability of the electrode structure. As shown in Fig. S12, $\mathrm{Co}_{3} \mathrm{O}_{4-x}$ covered with uniform SEI layer delivers superior structural integrity after 117 cycles. However, the $\mathrm{Co}_{3} \mathrm{O}_{4}$ electrode suffers from serious agglomeration, leading to the reduction of active sites and unstable structure of the electrode. The SEM image of the electrode after 70 cycles (Fig. S13) shows the same results. Therefore, we can conclude that the oxygen vacancies in $\mathrm{Co}_{3} \mathrm{O}_{4-x}$ are beneficial for maintaining the structural stability of the electrode. Thus, compared with $\mathrm{Co}_{3} \mathrm{O}_{4}, \mathrm{Co}_{3} \mathrm{O}_{4-x}$ exhibits higher cycling stability and rate performance because of its more abundant oxygen vacancies. In addition, the fully charged LIBs show a rapid self-discharge process in the first few minutes and the open-circuit voltage is maintained at approximately $2.0 \mathrm{~V}$, which indicates the low self-discharge rate of the LIBs [55].

As a result, $\mathrm{Co}_{3} \mathrm{O}_{4-x}$ exhibits a relatively stable capacity of $1120 \mathrm{~mA} \mathrm{~h} \mathrm{~g}^{-1}$ after 500 cycles. However, $\mathrm{Co}_{3} \mathrm{O}_{4}$ provides a discharge capacity of only $423 \mathrm{~mA} \mathrm{~h} \mathrm{~g}^{-1}$ after 500 cycles (Fig. 4e). The electrochemical properties of $\mathrm{Co}_{3} \mathrm{O}_{4}$-based anodes in the literature are summarized in Table S3. $\mathrm{Co}_{3} \mathrm{O}_{4-x}$ with rich oxygen vacancies in the present work has a higher capacity than previously reported $\mathrm{Co}_{3} \mathrm{O}_{4}$-based anodes at different current densities. In addition, $\mathrm{Co}_{3} \mathrm{O}_{4-x}$ with a load of $2 \mathrm{mg} \mathrm{cm}^{-2}$ exhibits high reversible capacity and excellent rate performance at $1 \mathrm{~A} \mathrm{~g}^{-1}$ (Fig. S14). The cycling data for $\mathrm{Co}_{3} \mathrm{O}_{4-x}$ with $10 \mathrm{wt} \%$ carbon black confirm that oxygen vacancies effectively improve the conductivity of $\mathrm{Co}_{3} \mathrm{O}_{4-x}$. As shown in Fig. S15, the electrode with $90 \mathrm{wt} \% \mathrm{Co}_{3} \mathrm{O}_{4-x}$ and $10 \mathrm{wt} \%$ carbon black exhibits excellent performance at different current densities and maintains $1100 \mathrm{~mA} \mathrm{~h} \mathrm{~g}^{-1}$ after 100 cycles at a current density of $1 \mathrm{~A} \mathrm{~g}^{-1}$. In addition, Fig. S2e displays the charge-discharge cycling performance of the $\mathrm{Fe}_{2} \mathrm{O}_{3-x}$ and $\mathrm{Fe}_{2} \mathrm{O}_{3}$ electrodes at $1 \mathrm{~A} \mathrm{~g} \mathrm{~g}^{-1}$. $\mathrm{Fe}_{2} \mathrm{O}_{3-x}$ remains a specific capacity of $1008 \mathrm{~mA} \mathrm{~h} \mathrm{~g}^{-1}$ approximately after 100 cycles. By contrast, $\mathrm{Fe}_{2} \mathrm{O}_{3}$ delivers an initial discharge capacity of $1729 \mathrm{~mA} \mathrm{~h} \mathrm{~g}^{-1}$ and then suffers a rapid decline in the following 10 cycles. The same situation also occurs on $\mathrm{NiO}_{1-x}$ and $\mathrm{NiO}$. The superior cycling performances of $\mathrm{Co}_{3} \mathrm{O}_{4-x}$, $\mathrm{Fe}_{2} \mathrm{O}_{3-x}$, and $\mathrm{NiO}_{1-x}$ can be rationally ascribed to the introduction of amounts of oxygen vacancies, which is favorable to the electrochemical lithium storage.

The separation of the diffusion and capacitive-controlled charge storage has been studied in detail by Dunn's group $[56,57]$. On the basis of their methods, the electrochemical kinetics analysis of $\mathrm{Co}_{3} \mathrm{O}_{4-x}$ based on the $\mathrm{CV}$ measurements at different scan rates $\left(0.1-1 \mathrm{mV} \mathrm{s}^{-1}\right)$ was adopted. As shown in Fig. 5a, a similar shape of curves and different peak values can be obtained under different scanning rates. Previous studies proved that the measured peak value $(i)$ and scan rate $(v)$ satisfy Equations (2) and (3):

$i=a v^{b}$,

$\log (i)=b \log (v)+\log (a)$.

The $b$ values can be calculated as the slope of the $\log (i)$ and $\log (v)$, which can clarify the mechanism of lithium storage. The $b$ value of 0.5 suggests that the capacity of the electrode is controlled by the diffusion process, while the $b$ value of 1 means a surface capacitive-controlled process [30,58]. As shown in Fig. $5 \mathrm{~b}$, the $b$ values of three peaks are $0.963,0.946$, and 1 , respectively, implying that the capacity of $\mathrm{Co}_{3} \mathrm{O}_{4-x}$ is mainly dominated by surface capacitive behavior.

$i(v)=k_{1} v+k_{2} v^{1 / 2}$.

In addition, Equation (4) is used to investigate the proportion of the surface capacitive contribution. The $k_{1} v$ represents the contribution of surface capacitive and the $k_{2} v^{1 / 2}$ represents the contribution of ion-diffusion, respectively [59]. As shown in Fig. $5 c$, the surface capacitive contribution proportion is $95.3 \%$ for the $\mathrm{Co}_{3} \mathrm{O}_{4-x}$ electrode at a scanning rate of $0.8 \mathrm{mV} \mathrm{s}^{-1}$. Fig. $5 \mathrm{~d}$ displays that the proportion of capacitive contribution increases mildly from $89.0 \%$ to $95.9 \%$ with the scanning rate ranging from 0.1 to $1 \mathrm{mV} \mathrm{s}^{-1}$, indicating that pseudocapacitive process controls the electrode specific capacity. Notably, the pseudocapacitive contribution of $\mathrm{Co}_{3} \mathrm{O}_{4}$ (Fig. S16) is much lower than that of $\mathrm{Co}_{3} \mathrm{O}_{4-x}$, suggesting that abundant oxygen vacancies 

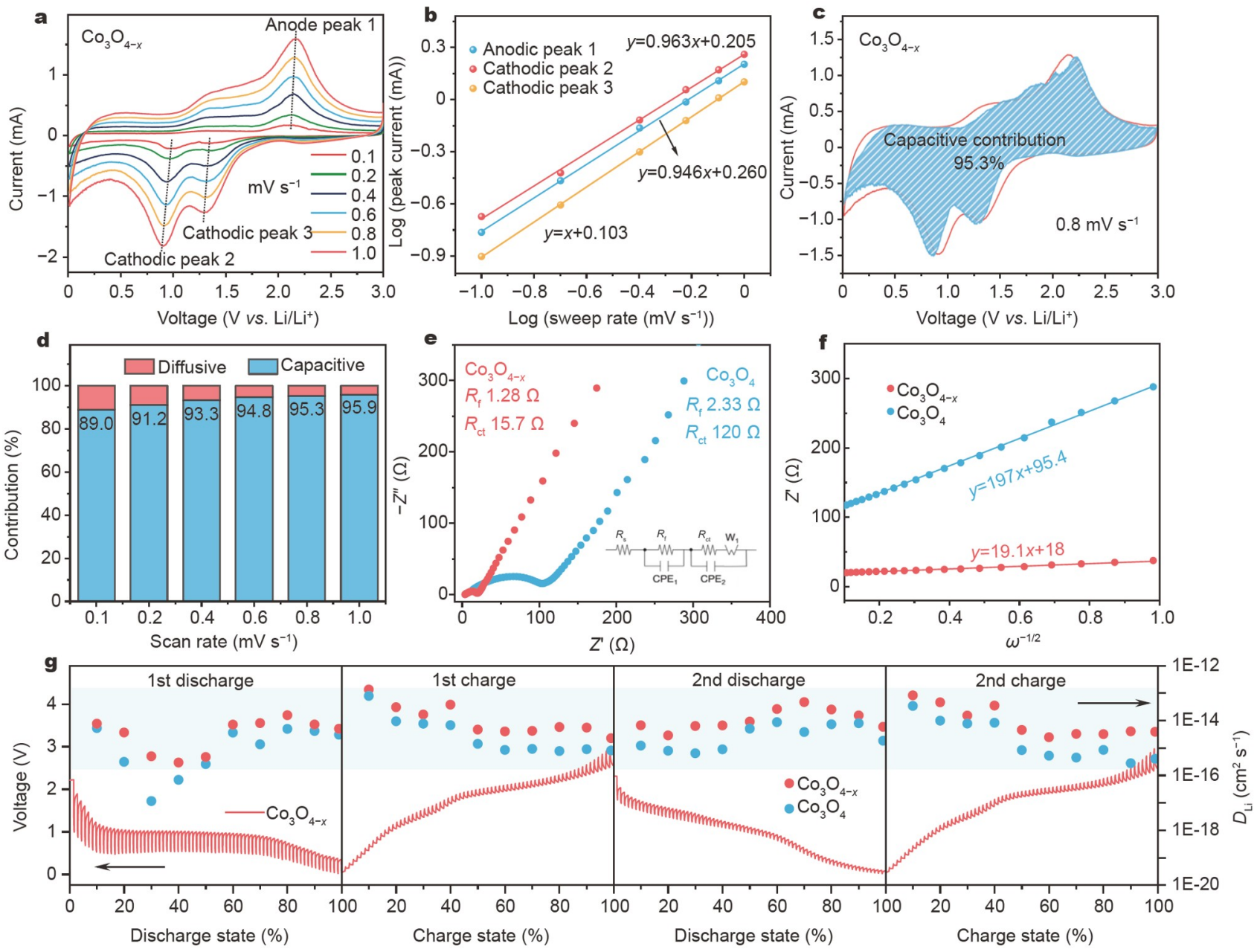

Figure 5 Electrochemical kinetic analyses of $\mathrm{Co}_{3} \mathrm{O}_{4-x}$. (a) $\mathrm{CV}$ curves measured at different scan rates from 0.1 to $1 \mathrm{mV} \mathrm{s}^{-1}$, (b) $b$ value according to the relationship of $\log (i)$ and $\log (v)$ at different peaks, (c) pseudocapacitive contributions (shaded area) at a scan rate of $0.8 \mathrm{mV} \mathrm{s}^{-1}$ and (d) ratio of pseudocapacitive contributions at different scan rates for $\mathrm{Co}_{3} \mathrm{O}_{4-x}$. (e) EIS of the $\mathrm{Co}_{3} \mathrm{O}_{4-x}$ and $\mathrm{Co}_{3} \mathrm{O}_{4}$ electrodes at $0.3 \mathrm{~A} \mathrm{~g} \mathrm{~g}^{-1}$ after 60 cycles, (f) relationship between the real part of the impedance and $\omega^{-1 / 2}$ of $\mathrm{Co}_{3} \mathrm{O}_{4-x}$ and $\mathrm{Co}_{3} \mathrm{O}_{4}$, and $(\mathrm{g})$ charge/discharge profiles of $\mathrm{Co}_{3} \mathrm{O}_{4-x}$ electrode in GITT test and the Li diffusivity coefficient during the first and second cycles.

can provide more reactive active sites for surface reaction and effectively improve the pseudocapacitive contribution $[30,60,61]$.

The above analysis shows that introducing more oxygen vacancies can increase the contribution of pseudocapacitance, thereby effectively improving the specific capacity and rate performance of the electrode material. In order to further reveal the significant influence of oxygen vacancies on electrode materials, electrochemical impedance spectroscopy (EIS) test was also performed. Fig. 5e displays the Nyquist plots of the $\mathrm{Co}_{3} \mathrm{O}_{4-x}$ and $\mathrm{Co}_{3} \mathrm{O}_{4}$ electrodes after 60 cycles at $0.3 \mathrm{~A} \mathrm{~g}^{-1}$. There are two depressed semicircles in the plots: one in the high-frequency region corresponding to the SEI layer resistance $\left(R_{\mathrm{f}}\right)$, and the other in the high-medium-frequency region corresponding to the charge-transfer resistance impedance $\left(R_{\mathrm{ct}}\right)$ [62]. After fitting with the equivalent circuit, the calculated $R_{\mathrm{f}}$ value of $\mathrm{Co}_{3} \mathrm{O}_{4-x}(1.28 \Omega)$ is smaller than that of $\mathrm{Co}_{3} \mathrm{O}_{4}(2.33 \Omega)$, and the $R_{\text {ct }}$ value of $\mathrm{Co}_{3} \mathrm{O}_{4-x}(15.7 \Omega)$ is also smaller than that of $\mathrm{Co}_{3} \mathrm{O}_{4}$ $(120 \Omega)$, suggesting that $\mathrm{Co}_{3} \mathrm{O}_{4-x}$ possesses faster charge transfer at the interface. To further confirm the impoved electrical conductivity by oxygen vacancies, the conductivity of $\mathrm{Co}_{3} \mathrm{O}_{4-x}$ and $\mathrm{Co}_{3} \mathrm{O}_{4}$ was measured by a four-point probe method for three times as shown in Fig. S17. The results prove that the conductivity of $\mathrm{Co}_{3} \mathrm{O}_{4-x}$ is approximately ten times higher than that of $\mathrm{Co}_{3} \mathrm{O}_{4}$ (Table S4). The above analysis indicates that $\mathrm{Co}_{3} \mathrm{O}_{4-x}$ has lower resistance and higher electronic conductivity than $\mathrm{Co}_{3} \mathrm{O}_{4}$ owing to the introduction of abundant oxygen vacancies [63].

The Li-ion diffusion coefficient $(D)$ of the samples complies with the following Equations (5) and (6):

$D=0.5\left(\frac{R T}{A n^{2} F^{2} C \sigma}\right)^{2}$

$Z^{\prime}=R_{\mathrm{s}}+R_{\mathrm{ct}}+\sigma \omega^{-1 / 2}$

where $R, T, A, F, C, \sigma$, and $R_{\mathrm{s}}$ correspond to the gas constant, absolute temperature, surface area, Faraday constant, concentration of $\mathrm{Li}^{+}$, Warburg factor, and Ohmic resistance, respectively. The Warburg factor $\sigma$ can be obtained after fitting the slope of $Z^{\prime}$ versus $\omega^{-1 / 2}$. As shown in Fig. 5f, the Warburg factor $\sigma$ values of the $\mathrm{Co}_{3} \mathrm{O}_{4-x}$ and $\mathrm{Co}_{3} \mathrm{O}_{4}$ electrodes are 19.1 and 197, respectively. Considering other parameters unchanged, the $D$ value of $\mathrm{Co}_{3} \mathrm{O}_{4-x}$ is two orders of magnitude higher than that of $\mathrm{Co}_{3} \mathrm{O}_{4}$. Therefore, $\mathrm{Co}_{3} \mathrm{O}_{4-x}$ with abundant oxygen vacancies processes a higher Li-ion diffusion coefficient than $\mathrm{Co}_{3} \mathrm{O}_{4}$. 
These analyses complied with the galvanostatic intermittent titration technique (GITT) measurements. The GITT was performed to calculate the Li-ion diffusion coefficient, which is satisfied with the following Equation (7):

$D_{\mathrm{Li}^{+}}=\frac{4}{\pi \tau}\left(\frac{n_{\mathrm{M}} V_{\mathrm{M}}}{S}\right)^{2}\left(\frac{\Delta E_{\mathrm{S}}}{\Delta E_{\tau}}\right)^{2}$,

where $n_{\mathrm{M}}$ and $V_{\mathrm{M}}$ are the molar mass and molar volume of the samples, respectively. $S$ stands for the active surface area of the electrodes, $\tau$ is the relaxation time, $\Delta E_{S}$ represents the potential change between steps, and $\Delta E_{\tau}$ represents potential change during the current pulse (Fig. S18) [47]. Fig. 5g presents the GITT test for $\mathrm{Co}_{3} \mathrm{O}_{4-x}$ and $\mathrm{Co}_{3} \mathrm{O}_{4}$ during the initial two cycles, and the calculation result is detailed in Table S5. The $D_{\mathrm{Li}^{+}}$value of $\mathrm{Co}_{3} \mathrm{O}_{4-x}$ ranges from $2.94 \times 10^{-16}$ to $8.34 \times 10^{-14} \mathrm{~cm}^{2} \mathrm{~s}^{-1}$, whereas the $D_{\mathrm{Li}^{+}}$value of $\mathrm{Co}_{3} \mathrm{O}_{4}$ ranges from $1.16 \times 10^{-18}$ to 3.44 $\times 10^{-14} \mathrm{~cm}^{2} \mathrm{~s}^{-1}$. In addition, $\mathrm{Co}_{3} \mathrm{O}_{4-x}$ possesses a higher $\mathrm{Li}^{+}$ diffusion coefficient than $\mathrm{Co}_{3} \mathrm{O}_{4}$ in different charge and discharge states, which can be explained by the accelerated diffusion kinetics owing to the introduced abundant oxygen vacancies. In general, the introduction of abundant oxygen vacancies can significantly improve the reaction kinetics by accelerating $\mathrm{Li}^{+}$diffusion, which agrees well with the increased interplanar spacing reflected in the XRD and HRTEM diagrams.

$\mathrm{Co}_{3} \mathrm{O}_{4-x}$ with abundant oxygen vacancies exhibits prodigious improvement in lithium storage as an anode, and the effect of oxygen vacancy was further explored. First, $\mathrm{Co}_{3} \mathrm{O}_{4-x}$ contains more oxygen vacancies and smaller particles than $\mathrm{Co}_{3} \mathrm{O}_{4}$, which can buffer volume expansion and maintain structural integrity. Second, the introduction of oxygen vacancies not only facilitates the insertion and extraction of lithium ions in the $\mathrm{Co}_{3} \mathrm{O}_{4-x}$ lattice but also improves electrical conductivity and reduced energy barriers. Third, the abundant oxygen vacancies provide abundant active sites for redox reactions and increase the ratio of capacitive contribution. All of these advantages mentioned above are beneficial for $\mathrm{Co}_{3} \mathrm{O}_{4-x}$ to maintain remarkable cycling capability and rate performance.

\section{CONCLUSION}

We successfully prepared different TMOs with abundant vacancies (e.g., $\mathrm{Co}_{3} \mathrm{O}_{4-x}, \mathrm{Fe}_{2} \mathrm{O}_{3-x}$, and $\mathrm{NiO}_{1-x}$ ) through a facile and general method by which oxygen vacancies were in situ introduced by carbonization treatment in air atmosphere. The as-prepared TMOs with abundant oxygen vacancies exhibit superior Li-ion storage performance over their counterparts without vacancies. In specific, the $\mathrm{Co}_{3} \mathrm{O}_{4-x}$ electrode shows a superior rate performance of $663 \mathrm{~mA} \mathrm{~h} \mathrm{~g}^{-1}$ even at the current density of $5 \mathrm{~A} \mathrm{~g}^{-1}$. Meanwhile, the $\mathrm{Co}_{3} \mathrm{O}_{4-x}$ electrode delivers a long-term reversible capacity of approximately $1120 \mathrm{~mA} \mathrm{~h} \mathrm{~g}^{-1}$ after 500 cycles at the current density of $1 \mathrm{~A} \mathrm{~g}^{-1}$. The significantly improved specific capacity and rate performance can be attributed to the accelerated Li-ion diffusion, enhanced electrical conductivity, reduced energy barriers, and increased capacitive contribution. This vacancy-engineering strategy can highlight the importance of designing an advanced electrode for energy storage and conversion from the perspective of fundamental material properties.

Received 31 August 2021; accepted 25 November 2021; published online 18 January 2022
1 Goodenough JB, Park KS. The Li-ion rechargeable battery: A perspective. J Am Chem Soc, 2013, 135: 1167-1176

$2 \mathrm{Lu} J$, Chen Z, Ma Z, et al. The role of nanotechnology in the development of battery materials for electric vehicles. Nat Nanotech, 2016, 11: $1031-1038$

3 Sun Y, Liu N, Cui Y. Promises and challenges of nanomaterials for lithium-based rechargeable batteries. Nat Energy, 2016, 1: 16071

4 Zhang B, Xia G, Chen W, et al. Controlled-size hollow magnesium sulfide nanocrystals anchored on graphene for advanced lithium storage. ACS Nano, 2018, 12: 12741-12750

5 Zheng M, Tang $\mathrm{H}$, Li L, et al. Hierarchically nanostructured transition metal oxides for lithium-ion batteries. Adv Sci, 2018, 5: 1700592

6 Reddy MV, Rao GVS, Chowdari BVR. Metal oxides and oxysalts as anode materials for Li ion batteries. Chem Rev, 2013, 113: 5364-5457

7 Zhao Y, Li X, Yan B, et al. Recent developments and understanding of novel mixed transition-metal oxides as anodes in lithium ion batteries. Adv Energy Mater, 2016, 6: 1502175

8 Wang J, Yang N, Tang $\mathrm{H}$, et al. Accurate control of multishelled $\mathrm{Co}_{3} \mathrm{O}_{4}$ hollow microspheres as high-performance anode materials in lithiumion batteries. Angew Chem Int Ed, 2013, 52: 6417-6420

$9 \mathrm{Lu} \mathrm{Y}, \mathrm{Yu} \mathrm{L}, \mathrm{Wu}$ M, et al. Construction of complex $\mathrm{Co}_{3} \mathrm{O}_{4} @ \mathrm{Co}_{3} \mathrm{~V}_{2} \mathrm{O}_{8}$ hollow structures from metal-organic frameworks with enhanced lithium storage properties. Adv Mater, 2018, 30: 1702875

10 Wu LL, Wang Z, Long $\mathrm{Y}$, et al. Multishelled $\mathrm{Ni}_{x} \mathrm{Co}_{3-x} \mathrm{O}_{4}$ hollow microspheres derived from bimetal-organic frameworks as anode materials for high-performance lithium-ion batteries. Small, 2017, 13: 1604270

11 Fang S, Bresser D, Passerini S. Transition metal oxide anodes for electrochemical energy storage in lithium- and sodium-ion batteries. Adv Energy Mater, 2019, 10: 1902485

12 Li WY, Xu LN, Chen J. $\mathrm{Co}_{3} \mathrm{O}_{4}$ nanomaterials in lithium-ion batteries and gas sensors. Adv Funct Mater, 2005, 15: 851-857

13 Wu ZS, Ren W, Wen L, et al. Graphene anchored with $\mathrm{Co}_{3} \mathrm{O}_{4}$ nanoparticles as anode of lithium ion batteries with enhanced reversible capacity and cyclic performance. ACS Nano, 2010, 4: 3187-3194

14 Huang Y, Fang Y, Lu XF, et al. $\mathrm{Co}_{3} \mathrm{O}_{4}$ hollow nanoparticles embedded in mesoporous walls of carbon nanoboxes for efficient lithium storage. Angew Chem Int Ed, 2020, 59: 19914-19918

15 Zhao Y, Dong W, Riaz MS, et al. "Electron-sharing" mechanism promotes $\mathrm{Co@} \mathrm{Co}_{3} \mathrm{O}_{4} / \mathrm{CNTs}$ composite as the high-capacity anode material of lithium-ion battery. ACS Appl Mater Interfaces, 2018, 10: 4364143649

16 Wang D, Yu Y, He H, et al. Template-free synthesis of hollow-structured $\mathrm{Co}_{3} \mathrm{O}_{4}$ nanoparticles as high-performance anodes for lithium-ion batteries. ACS Nano, 2015, 9: 1775-1781

17 Zhu S, Li J, Deng X, et al. Ultrathin-nanosheet-induced synthesis of 3D transition metal oxides networks for lithium ion battery anodes. Adv Funct Mater, 2017, 27: 1605017-1605025

18 Cheng G, Kou T, Zhang J, et al. $\mathrm{O}_{2}{ }^{2-} / \mathrm{O}^{-}$functionalized oxygen-deficient $\mathrm{Co}_{3} \mathrm{O}_{4}$ nanorods as high performance supercapacitor electrodes and electrocatalysts towards water splitting. Nano Energy, 2017, 38: $155-166$

19 Li Y, Tan B, Wu Y. Mesoporous $\mathrm{Co}_{3} \mathrm{O}_{4}$ nanowire arrays for lithium ion batteries with high capacity and rate capability. Nano Lett, 2008, 8: 265270

20 Hou C, Hou Y, Fan Y, et al. Oxygen vacancy derived local build-in electric field in mesoporous hollow $\mathrm{Co}_{3} \mathrm{O}_{4}$ microspheres promotes high-performance Li-ion batteries. J Mater Chem A, 2018, 6: 6967-6976

$21 \mathrm{Gu} \mathrm{D}, \mathrm{Li} \mathrm{W}$, Wang F, et al. Controllable synthesis of mesoporous peapod-like $\mathrm{Co}_{3} \mathrm{O}_{4} @$ carbon nanotube arrays for high-performance lithium-ion batteries. Angew Chem Int Ed, 2015, 54: 7060-7064

22 Tang C, Zhang Q. Nanocarbon for oxygen reduction electrocatalysis: Dopants, edges, and defects. Adv Mater, 2017, 29: 1604103

$23 \mathrm{Xu} \mathrm{L}$, Jiang Q, Xiao Z, et al. Plasma-engraved $\mathrm{Co}_{3} \mathrm{O}_{4}$ nanosheets with oxygen vacancies and high surface area for the oxygen evolution reaction. Angew Chem Int Ed, 2016, 55: 5277-5281

24 Lin Z, Shen S, Wang Z, et al. Laser ablation in air and its application in catalytic water splitting and Li-ion battery. iScience, 2021, 24: 102469

25 Lin Z, Xiao BB, Wang Z, et al. Planar-coordination $\mathrm{PdSe}_{2}$ nanosheets as 
highly active electrocatalyst for hydrogen evolution reaction. Adv Funct Mater, 2021, 31: 2102321

26 Zhong W, Wang Z, Gao N, et al. Coupled vacancy pairs in Ni-doped CoSe for improved electrocatalytic hydrogen production through topochemical deintercalation. Angew Chem Int Ed, 2020, 59: 2274322748

27 Lee S, Jin W, Kim SH, et al. Oxygen vacancy diffusion and condensation in lithium-ion battery cathode materials. Angew Chem Int Ed, 2019, 58: 10478-10485

28 Wang Y, Xiao X, Li Q, et al. Synthesis and progress of new oxygenvacant electrode materials for high-energy rechargeable battery applications. Small, 2018, 14: 1802193

29 Deng S, Zhang Y, Xie D, et al. Oxygen vacancy modulated $\mathrm{Ti}_{2} \mathrm{Nb}_{10} \mathrm{O}_{29-x}$ embedded onto porous bacterial cellulose carbon for highly efficient lithium ion storage. Nano Energy, 2019, 58: 355-364

30 Kim HS, Cook JB, Lin H, et al. Oxygen vacancies enhance pseudocapacitive charge storage properties of $\mathrm{MoO}_{3-x}$. Nat Mater, 2017, 16: 454460

31 Zhang X, Deng S, Zeng Y, et al. Oxygen defect modulated titanium niobium oxide on graphene arrays: An open-door for high-performance $1.4 \mathrm{~V}$ symmetric supercapacitor in acidic aqueous electrolyte. Adv Funct Mater, 2018, 28: 1805618

32 Qiu J, Li S, Gray E, et al. Hydrogenation synthesis of blue $\mathrm{TiO}_{2}$ for high-performance lithium-ion batteries. J Phys Chem C, 2014, 118: 8824-8830

33 Tang ZK, Xue YF, Teobaldi G, et al. The oxygen vacancy in Li-ion battery cathode materials. Nanoscale Horiz, 2020, 5: 1453-1466

34 Li L, Xie Z, Jiang G, et al. Efficient laser-induced construction of oxygen-vacancy abundant nano- $\mathrm{ZnCo}_{2} \mathrm{O}_{4} /$ porous reduced graphene oxide hybrids toward exceptional capacitive lithium storage. Small, 2020, 16: 2001526

35 Gan $\mathrm{Q}, \mathrm{He} \mathrm{H}$, Zhao $\mathrm{K}$, et al. Plasma-induced oxygen vacancies in urchin-like anatase titania coated by carbon for excellent sodium-ion battery anodes. ACS Appl Mater Interfaces, 2018, 10: 7031-7042

36 Lin T, Yang C, Wang Z, et al. Effective nonmetal incorporation in black titania with enhanced solar energy utilization. Energy Environ Sci, 2014, 7: 967

37 Wang G, Yang Y, Ling Y, et al. An electrochemical method to enhance the performance of metal oxides for photoelectrochemical water oxidation. J Mater Chem A, 2016, 4: 2849-2855

$38 \mathrm{Xu} \mathrm{M}$, Xia Q, Yue J, et al. Rambutan-like hybrid hollow spheres of carbon confined $\mathrm{Co}_{3} \mathrm{O}_{4}$ nanoparticles as advanced anode materials for sodium-ion batteries. Adv Funct Mater, 2018, 29: 1807377

39 Hao Z, Chen Q, Dai W, et al. Oxygen-deficient blue $\mathrm{TiO}_{2}$ for ultrastable and fast lithium storage. Adv Energy Mater, 2020, 10: 1903107

40 Chong SV, Kadowaki K, Xia J, et al. Interesting magnetic behavior from reduced titanium dioxide nanobelts. Appl Phys Lett, 2008, 92: 232502

41 Zuo F, Wang L, Wu T, et al. Self-doped $\mathrm{Ti}^{3+}$ enhanced photocatalyst for hydrogen production under visible light. J Am Chem Soc, 2010, 132: 11856-11857

42 Yin G, Huang X, Chen T, et al. Hydrogenated blue titania for efficient solar to chemical conversions: Preparation, characterization, and reaction mechanism of $\mathrm{CO}_{2}$ reduction. ACS Catal, 2018, 8: 1009-1017

43 Kang J, Kim J, Lee S, et al. Breathable carbon-free electrode: Black $\mathrm{TiO}_{2}$ with hierarchically ordered porous structure for stable $\mathrm{Li}-\mathrm{O}_{2}$ battery. Adv Energy Mater, 2017, 7: 1700814

44 Yan C, Chen G, Zhou X, et al. Template-based engineering of carbondoped $\mathrm{Co}_{3} \mathrm{O}_{4}$ hollow nanofibers as anode materials for lithium-ion batteries. Adv Funct Mater, 2016, 26: 1428-1436

45 Wang $\mathrm{Z}, \mathrm{Xu} \mathrm{W}$, Chen $\mathrm{X}$, et al. Defect-rich nitrogen doped $\mathrm{Co}_{3} \mathrm{O}_{4} / \mathrm{C}$ porous nanocubes enable high-efficiency bifunctional oxygen electrocatalysis. Adv Funct Mater, 2019, 29: 1902875

46 Su D, Dou S, Wang G. Anatase $\mathrm{TiO}_{2}$ : Better anode material than amorphous and rutile phases of $\mathrm{TiO}_{2}$ for Na-ion batteries. Chem Mater, 2015, 27: 6022-6029

47 Li Z, Dong Y, Feng J, et al. Controllably enriched oxygen vacancies through polymer assistance in titanium pyrophosphate as a super anode for $\mathrm{Na} / \mathrm{K}$-ion batteries. ACS Nano, 2019, 13: 9227-9236

48 Huang G, Zhang F, Du X, et al. Metal organic frameworks route to in situ insertion of multiwalled carbon nanotubes in $\mathrm{Co}_{3} \mathrm{O}_{4}$ polyhedra as anode materials for lithium-ion batteries. ACS Nano, 2015, 9: 15921599

49 Yu M, Sun Y, Du H, et al. Hollow porous carbon spheres doped with a low content of $\mathrm{Co}_{3} \mathrm{O}_{4}$ as anode materials for high performance lithiumion batteries. Electrochim Acta, 2019, 317: 562-569

50 Cabana J, Monconduit L, Larcher D, et al. Beyond intercalation-based Li-ion batteries: The state of the art and challenges of electrode materials reacting through conversion reactions. Adv Mater, 2010, 22: E170E192

$51 \mathrm{Hu} \mathrm{Y}, \mathrm{Li} \mathrm{Z}, \mathrm{Hu} \mathrm{Z}$, et al. Engineering hierarchical $\mathrm{CoO}$ nanospheres wrapped by graphene via controllable sulfur doping for superior $\mathrm{Li}$ ion storage. Small, 2020, 16: 2003643

52 Zhu J, Tu W, Pan H, et al. Self-templating synthesis of hollow $\mathrm{Co}_{3} \mathrm{O}_{4}$ nanoparticles embedded in N,S-dual-doped reduced graphene oxide for lithium ion batteries. ACS Nano, 2020, 14: 5780-5787

53 Sun $\mathrm{H}$, Xin G, Hu T, et al. High-rate lithiation-induced reactivation of mesoporous hollow spheres for long-lived lithium-ion batteries. Nat Commun, 2014, 5: 4526

54 Dou Y, Xu J, Ruan B, et al. Atomic layer-by-layer $\mathrm{Co}_{3} \mathrm{O}_{4} /$ graphene composite for high performance lithium-ion batteries. Adv Energy Mater, 2016, 6: 1501835

55 Shi M, Xiao P, Lang J, et al. Porous $\mathrm{g}_{-} \mathrm{C}_{3} \mathrm{~N}_{4}$ and MXene dual-confined $\mathrm{FeOOH}$ quantum dots for superior energy storage in an ionic liquid. Adv Sci, 2019, 7: 1901975

56 Augustyn V, Simon P, Dunn B. Pseudocapacitive oxide materials for high-rate electrochemical energy storage. Energy Environ Sci, 2014, 7: 1597

57 Augustyn V, Come J, Lowe MA, et al. High-rate electrochemical energy storage through $\mathrm{Li}^{+}$intercalation pseudocapacitance. Nat Mater, 2013, 12: $518-522$

58 Zhang $\mathrm{X}$, Wang $\mathrm{H}$, Shui $\mathrm{L}$, et al. Ultrathin $\mathrm{Ni}(\mathrm{OH})_{2}$ layer coupling with graphene for fast electron/ion transport in supercapacitor. Sci China Mater, 2021, 64: 339-348

59 Ma Y, Ma Y, Bresser D, et al. Cobalt disulfide nanoparticles embedded in porous carbonaceous micro-polyhedrons interlinked by carbon nanotubes for superior lithium and sodium storage. ACS Nano, 2018, 12: $7220-7231$

60 Deng X, Wei Z, Cui C, et al. Oxygen-deficient anatase $\mathrm{TiO}_{2} @ \mathrm{C}$ nanospindles with pseudocapacitive contribution for enhancing lithium storage. J Mater Chem A, 2018, 6: 4013-4022

61 He H, Huang D, Tang Y, et al. Tuning nitrogen species in threedimensional porous carbon via phosphorus doping for ultra-fast potassium storage. Nano Energy, 2019, 57: 728-736

62 Wang $\mathrm{HE}$, Zhao X, Li X, et al. $\mathrm{rGO} / \mathrm{SnS}_{2} / \mathrm{TiO}_{2}$ heterostructured composite with dual-confinement for enhanced lithium-ion storage. J Mater Chem A, 2017, 5: 25056-25063

$63 \mathrm{Xu} \mathrm{Y}$, Zhou M, Wang X, et al. Enhancement of sodium ion battery performance enabled by oxygen vacancies. Angew Chem Int Ed, 2015, 54: $8768-8771$

Acknowledgements This work was supported by the National Natural Science Foundation of China (92163117 and 52072389) and the Program of Shanghai Academic Research Leader (20XD1424300).

Author contributions Wang J and Ma R initiated the research. Wang X prepared the samples and conducted experimental measurements on the samples. All authors participated in the discussion of the results. Wang X, Ma $\mathrm{R}$ and Wang J wrote the paper.

Conflict of interest The authors declare that they have no conflict of interest.

Supplementary information Experimental details and supporting data are available in the online version of the paper. 


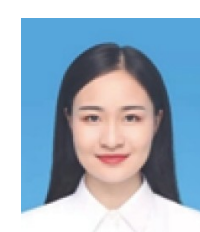

Xunlu Wang is a PhD candidate in Prof. Jiacheng Wang's group at the State Key Laboratory of High-Performance Ceramics and Superfine Microstructure, Shanghai Institute of the Ceramics, Chinese Academy of Sciences, Shanghai, China. Her current research focuses on the nanostructured electrode materials for $\mathrm{Li}$ ion batteries and highly efficient non-precious metal catalysts.

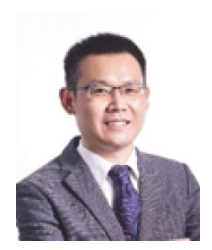

Ruguang Ma received his $\mathrm{PhD}$ degree in materials science from the City University of Hong Kong in 2013. He is currently a professor at the College of Materials Science and Engineering, Suzhou University of Science and Technology. His research interests include the design and synthesis of highly efficient non-precious metal catalysts and new nanostructured electrode materials for $\mathrm{Li}$ ion batteries, supercapacitors and metal-oxygen batteries.

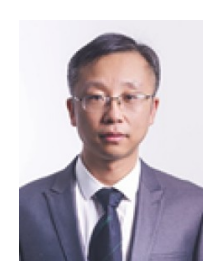

Jiacheng Wang is a full professor and group leader of the Electrocatalytic Materials and Energy Devices Group at Shanghai Institute of Ceramics, Chinese Academy of Sciences. He was awarded several famous talent projects including Chinese Academy of Sciences Distinguished Talent, Shanghai Academic Research Leader, Alexander von Humboldt Fellow, the Japan Society for the Promotion of Science (JSPS) Postdoctoral Fellow for Foreign Researcher, and Marie Curie Intra-European Fellow. His current research interests include rational design and preparation of high-performance electrocatalysts for advanced energy storage and conversion.

\section{氧空位提高金属氧化物锂离子扩散动力学及储锂性能}

王寻路 ${ }^{1,2}$, 刘婕 ${ }^{1}$, 胡一帆 1,2 , 马汝广 ${ }^{1,3 *}$, 王家成 $1,2^{*}$

摘要 转化反应过程中锂离子电池负极材料面临容量快速衰减和动力 学缓慢的问题. 氧空位缺陷可以有效调节过渡金属氧化物(TMO)基电 极材料的内在特性, 但是, 氧空位对电极材料性能的影响机制尚不清 楚. 本研究通过简单的方法, 将丰富的氧空位原位引入到不同 $\mathrm{TMO}$ (例 如 $\mathrm{Co}_{3} \mathrm{O}_{4} 、 \mathrm{Fe}_{2} \mathrm{O}_{3}$ 和 $\mathrm{NiO}$ )的晶格中. 以 $\mathrm{Co}_{3} \mathrm{O}_{4}$ 为例, $\mathrm{Co}_{3} \mathrm{O}_{4-x}$ 中的氧空位能 够有效加快界面处的电荷转移, 显著提高电导率和赝电容贡献. 理论计 算表明, 氧空位的引入能够降低锂嵌入能垒, 且增加费米能级附近的态 密度, 有利于离子和电子传输. 因此, 富含氧空位的 TMO 表现出更优异 的循环稳定性和倍率性能. 本研究可以为设计用于能源应用的其他 TMO电极材料提供参考. 